\title{
Retrofitted Green Roofs and Walls and Improvements in Thermal Comfort.
}

\author{
Renato Castiglia Feitosa ${ }^{1, \text { a) }}$ and Sara Wilkinson ${ }^{2, b)}$ \\ ${ }^{1}$ Researcher at Oswaldo Cruz Foundation (Fiocruz), Department of Sanitation and Environmental Health of \\ National School of Public Health, Brazil. \\ ${ }^{2}$ School of Built Environment, Faculty of Design Architecture and Building UTS, Australia.

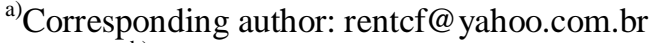 \\ b) sara.wilkinson@uts.edu.au
}

\begin{abstract}
Increased urbanization has led to a worsening in the quality of life for many people living in large cities in respect of the urban heat island effect and increases of indoor temperatures in housing and other buildings. A solution may be to retrofit existing environments to their former conditions, with a combination of green infrastructures applied to existing walls and rooftops. Retrofitted green roofs may attenuate housing temperature. However, with tall buildings, facade areas are much larger compared to rooftop areas, the role of green walls in mitigating extreme temperatures is more pronounced. Thus, the combination of green roofs and green walls is expected to promote a better thermal performance in the building envelope. For this purpose, a modular vegetated system is adopted for covering both walls and rooftops. Rather than temperature itself, the heat index, which comprises the combined effect of temperature and relative humidity is used in the evaluation of thermal comfort in small scale experiments performed in Sydney Australia, where identical timber framed structures prototypes (vegetated and non-vegetated) are compared. The results have shown a different understanding of thermal comfort improvement regarding heat index rather than temperature itself. The combination of green roof and walls has a valid role to play in heat index attenuation.
\end{abstract}

\section{INTRODUCTION}

High density population areas have led to a worsening in the quality of life for many people in large cities in respect of the urban heat island effect and increases of indoor temperatures in residential and other buildings. To worsen the present scenario, the total urban population is said to increase to $66 \%$ of world population or 6.3 billion people by 2050 [1]. This is also coupled with overall global temperature increases occurring as a result of global warming and climate change [2]. Consequently, as a result of population and temperature increases, there a potential trend for health issues related to heat stress especially in elderly populations [3, 4].

Retrofitting existing buildings may contribute as a partial solution to these problems through a combination of green roof and green walls applied to existing rooftops and walls, respectively. As presented by Wilkinson and Castiglia Feitosa [5] green roofs may attenuate housing temperature. However it is important to highlight that due to the common tall characteristics of buildings, facade areas are substantially larger than those from rooftops. Thus, it is expected a more pronounced effect of green walls in attenuating housing temperatures [6]. However the combination of green roof and green walls is likely to provide a better thermal performance in the building envelope. In this way the present work intended to investigate to what extent this was the case. With this goal, a modular vegetated system is adopted for covering both rooftops and walls.

Rather than temperature itself, the heat index that encompasses the simultaneous effect of relative humidity and temperature, is used as the indicator of thermal comfort in Sydney - Australia using small scale experiments that compares two identical timber framed structure prototypes where one is fully covered with vegetation (walls and rooftop), and the other is not.

Several countries are expected to be effected heat waves in the upcoming years due to climate change impacts. In addition, according to Mertz et al. [7] many developing countries are predicted to be affected by increased temperatures. Thus, retrofitting existing buildings in a short time frame may comprise a suitable and viable solution. 
The present research sought to evaluate the thermal performance of lightweight and low cost systems in retrofitting green walls and rooftops from existing buildings with no need of structural reinforcement. It also sets out the rationale for research design and experimental setups. The results presented show the performance of the vegetated structure in heat index attenuation, when compared to the non-vegetated structure.

\section{METHODS}

The methodology adopted herein encompasses the use of adaptive techniques that aim to mitigate the problems caused by increasing urbanisation, such as heat island effects and high internal housing temperatures promoted by direct solar radiation. A proposed solution for this issue is the use of lightweight vegetated modular systems that allow planting, cultivation and maintenance to be undertaken off site. This low cost technique is a simple and straightforward application for existing walls and rooftops. However, due to the significant and growing numbers of tall buildings in urban centres, facades become more relevant than rooftop areas in terms of heat exchange as they offer a greater area to plant out which is also highly visible to many people increasing the Biophilic effect [8].

\section{Experimental Procedure}

In order to evaluate the combined effect of green roofs and green walls an experimental setup was established at the University of Technology Sydney (UTS) Australia, using a selection of succulent plants due to their low risk of fire, drought resistance and good capability of development in shallow substrates that, in turn, avoided the need of structural reinforcement.

As shown in the Fig. 1 the adopted system comprise modular characteristics that make it possible to apply previously planted vegetated modules onto existing roof coverings, comprising either metal sheeting, roof tiles, or concrete roof slabs. To avoid the soil particles loss, it used a permeable fabric that separates the substrate from drainage and storage system that can retro feed the soil with water vapour during the evaporation process. Additional details about the methodology can be found in Wilkinson and Castiglia Feitosa [9].

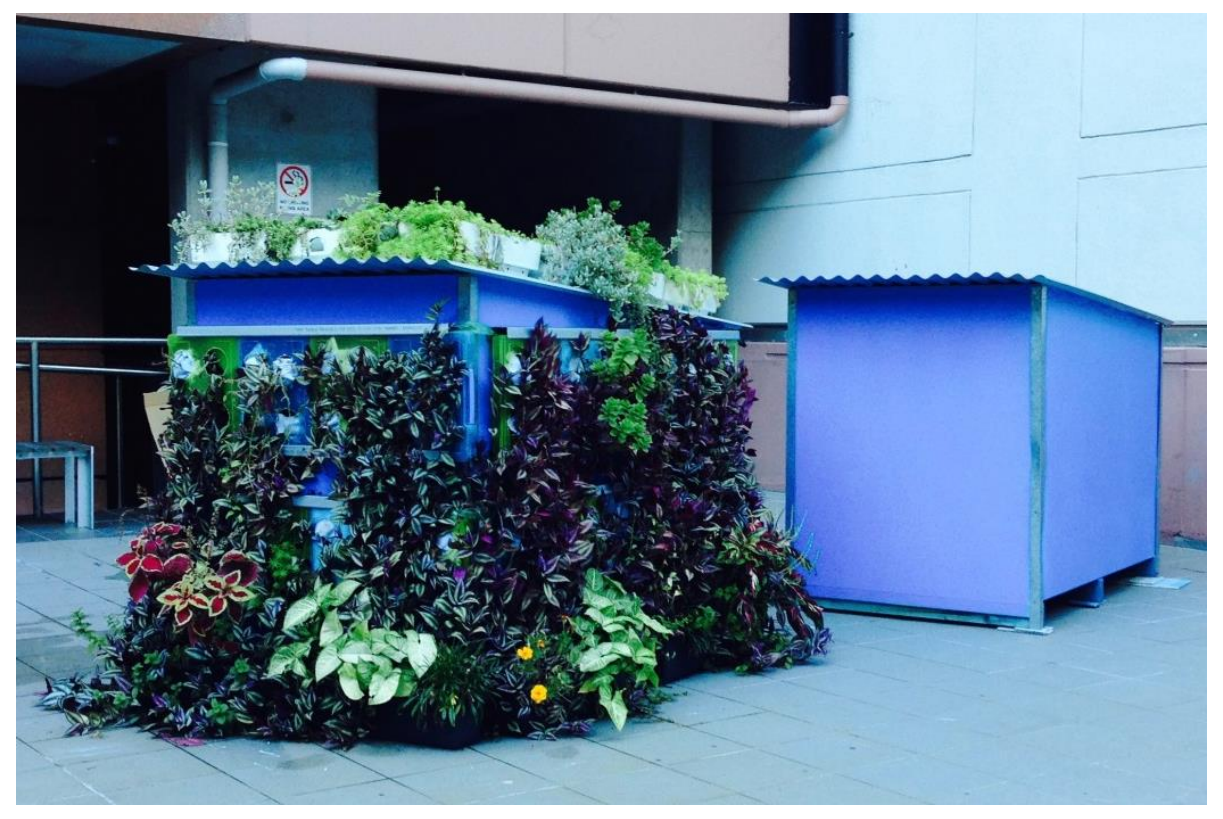

FIGURE 1. Green roof and green walls experimental setup.

The green wall methodology was designed originally at Oswaldo Cruz Foundation (Fiocruz) Brazil is not presented in this paper, but is described by Wilkinson and Castiglia Feitosa [9]. In the experimental setup performed in Sydney plastic closed boxes, with six circular shaped openings drilled into the outer face in a three row and two column array, were used as containers for soil and plants. In this case, $5 \mathrm{~cm}$ of substrate is placed into the container 
before being covered by geotextile fabric, and then sealed by the cover of the container box. Once this was completed, the plants were set in soil through small cuts in the geotextile fabric, and after the plants had established themselves, the boxes are placed by in " $U$ " shaped metal profiles screw fixed to the external wall. The combined effect of vegetated roof and walls in heat index attenuation is performed by comparing two identical prototypes constructed with a $100 \mathrm{~mm}$ thick timber framed structure covered with $13 \mathrm{~mm}$ thick cement board, where one is fully covered with vegetation on walls and the roof, a profiled metal sheet covering, and the other structure is not (see Fig.1).

\section{Heat Index Evaluation}

Records of temperature and relative humidity were taken every 30 minutes, simultaneously inside the vegetated and non-vegetated prototypes by using data loggers supplied by Extech RHT10 over 92 days, from January 19th 2016 to April 20th 2016.

The heat index expresses the "apparent temperature" in degrees Celsius or Fahrenheit as a combined effect of relative humidity and air temperature. It is used by the National Weather Service (NWS), U.S. Government that provides weather forecasts and warnings of hazardous weather. Instead of considering only the influence of temperature on thermal comfort evaluation, the "apparent temperature" indicates the heat sensation due to the effect of relative humidity that indicates the amount of moisture in the air [10].

Relative humidity plays a relevant role on thermal comfort evaluation, once it is responsible for regulating the evaporation rate of sweat from the skin that responds to the cooling of the human body. Higher levels of relative humidity mitigate sweat evaporation from the skin, and increase the sensation of heat experienced by human beings [10].

In terms of environmental health research, the work carried by Steadman [11] provides the basis for the so called Steadman's apparent temperature. It translates the combined effect of relative humidity and temperature into a scale called heat index that has the same units of temperature.

Anderson et al. [6] investigated and compared 21 algorithms that calculate heat index as a function of temperature and relative humidity, or dew point temperature. These authors pointed out that NWS algorithm [12], presented in the flowchart below (Fig.2), had the best fit Steadman's table [11], and as a result it was chosen to calculate heat index in the present work. It is worth highlighting that initially heat index values were calculated using temperature unit measured in degrees Fahrenheit. These results were later converted to degrees Celsius.

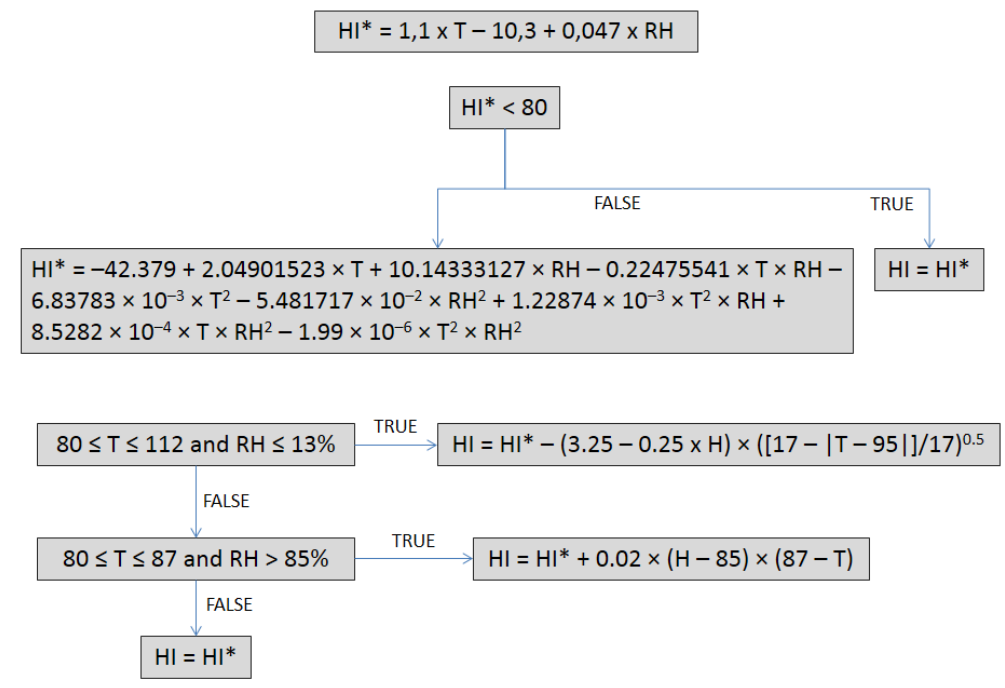

FIGURE 2. Flowchart of the algorithm of heat index (HI) calculation used by NWS based on air temperature in degrees Fahrenheit $(\mathrm{T})$ and relative humidity in per cent $(\mathrm{RH})$. 
The risk analysis assessment in terms of heat stress is related to heat index according to the following heat advisory categories described in Table 1, which evaluates the likelihood of heat disorders with prolonged exposure or strenuous activity.

TABLE 1. Classification of heat advisories in United States according to NWS.

\begin{tabular}{lrc}
\hline \multicolumn{1}{c}{ Categories } & Heat Index & Possible Heat Disorders for People in High Risk Groups \\
\hline $\begin{array}{l}\text { Extreme } \\
\text { danger }\end{array}$ & $>54^{\circ} \mathrm{C}$ & Heat stroke or sunstroke likely. \\
Danger & $41-54^{\circ} \mathrm{C}$ & $\begin{array}{c}\text { Sunstroke, muscle cramps, and/or heat exhaustion likely. } \\
\text { Heatstroke possible with prolonged exposure and/or physical } \\
\text { activity. }\end{array}$ \\
$\begin{array}{l}\text { Extreme } \\
\text { caution } \\
\text { Caution }\end{array}$ & $32-41^{\circ} \mathrm{C}$ & $\begin{array}{c}\text { Sunstroke, muscle cramps, and/or heat exhaustion possible with } \\
\text { prolonged exposure and/or physical activity. }\end{array}$ \\
\hline
\end{tabular}

\section{RESULTS AND DISCUSSION}

Figure 3 presents a comparison between relative humidity, temperature, and the calculated heat index according to the NSW algorithm, during a 92 day-period that comprised mostly summer and mid-autumn seasons in Sydney. In addition, Table 2 summarises the maximum, minimum and average of the measured parameters, relative humidity and temperature, and their associated values of heat index for both non-vegetated and vegetated structures.

TABLE 2. Sydney maximum, minimum and average limits of temperature, relative humidity and heat index.

\begin{tabular}{lcccccc}
\hline Categories & \multicolumn{2}{c}{ Temperature } & \multicolumn{2}{c}{ Relative Humidity } & Heat Index & Non- \\
& Vegetated & $\begin{array}{c}\text { Non- } \\
\text { vegetated }\end{array}$ & Vegetated & $\begin{array}{c}\text { Non- } \\
\text { vegetated }\end{array}$ & Vegetated & Non-vegetated \\
\hline Maximum & 33.0 & 42.0 & 88.5 & 81.3 & 36.3 & 55.9 \\
Minimum & 15.5 & 15.4 & 38.6 & 36.3 & 15.5 & 15.4 \\
Average & 23.4 & 24.8 & 74 & 65.5 & 23.6 & 25.6 \\
\hline
\end{tabular}

All limits of relative humidity levels were higher for the vegetated structure, when compared to the nonvegetated one. It indicated an influx of moisture into the vegetated prototype due to evapotranspiration process of plants. In the Fig. 3 it can be seen that the records of relative humidity in the vegetated structure were permanently higher than those from the non-vegetated structure.

The maximum temperatures were registered during the daytime, whereas the lowest occurred during early morning hours. When compared to temperature the higher levels of heat index were substantially higher. However, according to the algorithm used, the minimum values of heat index and temperature are about the same for temperatures lower than $26.7^{\circ} \mathrm{C}$.

Based on the temperature attenuation, as depicted in Fig. 3 the temperature differences varied from $-1.1^{\circ} \mathrm{C}$ to $12.0^{\circ} \mathrm{C}$. The positive differences mean that the non-vegetated structure was warmer than the vegetated structure during the daytime, while the negative differences (vegetated structure warmer than non-vegetated structure) were commonly registered in the night-time and early morning.

In terms of heat index, the difference between the non-vegetated, and the vegetated structure varied from $-3.4^{\circ} \mathrm{C}$ to $21^{\circ} \mathrm{C}$. It can be highlighted that in terms of heat index the influence of vegetation is even more pronounced when comparing vegetated to non-vegetated structure. As a result it is evident an increase in the ranges of temperature attenuation. The temperature showed to be more effective on heat index. However, relative higher levels of relative humidity in vegetated structures may counteract the effects of attenuation of temperature promoted by the vegetation. In the present case besides the vegetated structure having higher relative humidity levels than nonvegetated structure, such levels were not substantial to offset the effects of relative humidity. 

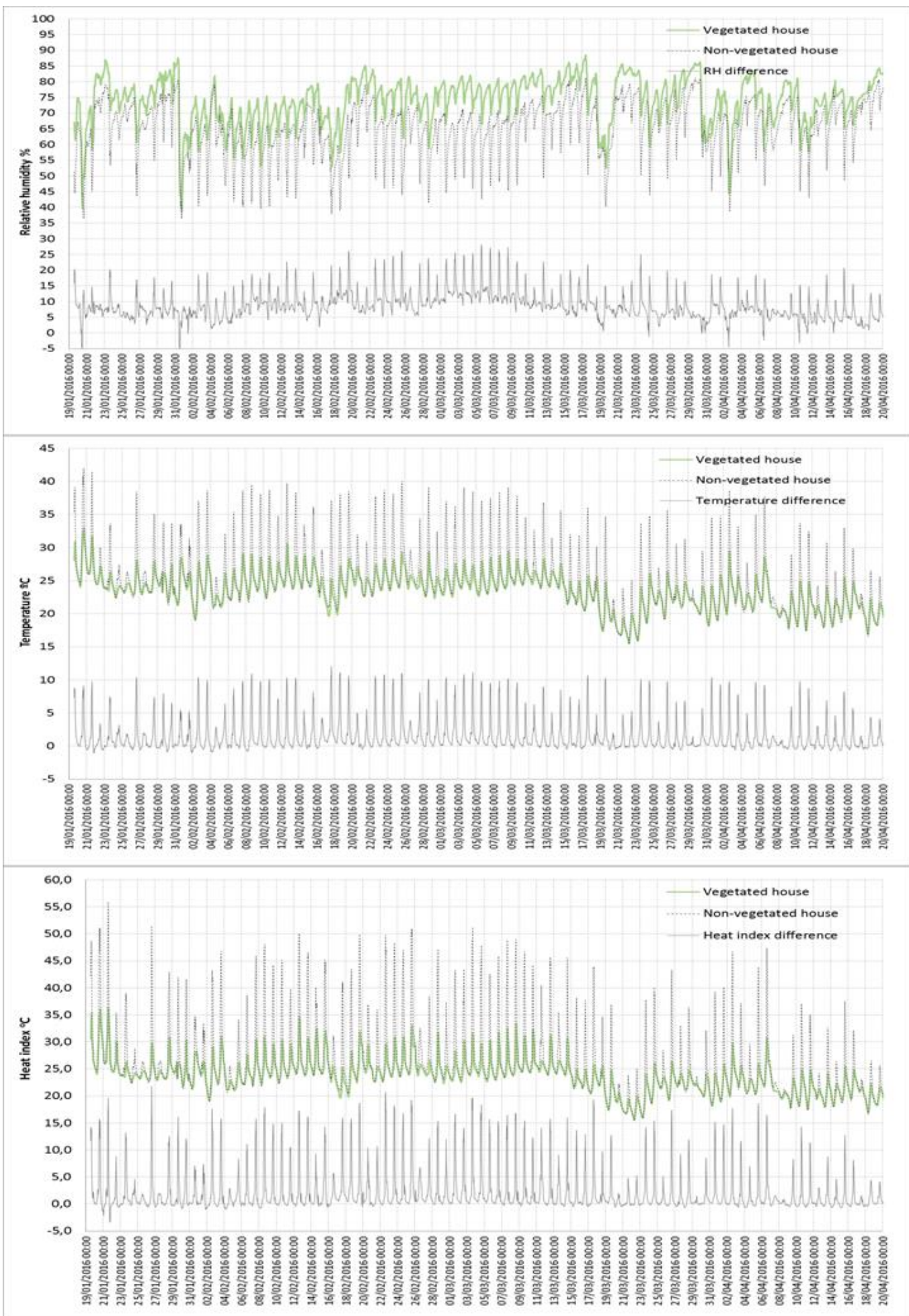

FIGURE 3. Comparisons between relative humidity, temperature, and calculated heat index

In the results presented, the efficiency in temperature and heat index attenuation is relevant. Table 3 presents a summary of the measured parameters of temperature and relative humidity, and their respective calculated values of heat index. 
TABLE 3. Sydney maximum, minimum and average limits of temperature, relative humidity and heat index.

\begin{tabular}{lccccc}
\hline Parameters & & $\begin{array}{c}\text { Non-vegetated } \\
(\mathbf{N V})\end{array}$ & Vegetated & $\begin{array}{c}\text { Difference } \\
(\mathbf{N V})-(\mathbf{V})\end{array}$ & $\begin{array}{c}\text { Simultaneous } \\
\text { Difference }\end{array}$ \\
\hline Temperature & Maximum & 42.0 & 33.0 & 9.0 & 12.0 \\
& Minimum & 15.4 & 15.5 & -0.1 & -1.1 \\
\multirow{3}{*}{ Relative Humidity } & Average & 24.8 & 23.4 & 1.4 & - \\
& Maximum & 81.3 & 88.5 & -7.2 & 21.8 \\
Heat Index & Minimum & 36.3 & 38.6 & -2.3 & -3.4 \\
& Average & 65.5 & 74.0 & -8.5 & - \\
& Maximum & 55.9 & 36.3 & 19.6 & 28.1 \\
& Minimum & 15.4 & 15.5 & -0.1 & -5.5 \\
\hline
\end{tabular}

Compared to the previous work undertaken by Wilkinson and Castiglia Feitosa [9] that considered only the influence of vegetated roofs in attenuation of internal temperature in metallic sheds, a new set of experiments using different building materials was carried out to evaluate the simultaneous of vegetated walls and roof.

Comparing the both timber-framed structures, the experiments showed significant differences between the nonvegetated and the vegetated prototypes. The dark blue colour used on the walls of the prototypes, increased the internal temperature differences to a greater extent, due to the contrast of the surface temperatures between the uncovered walls and shaded walls by vegetation

The evaluation of thermal comfort is not only influenced by temperature but also by relative humidity levels. Compared to non-vegetated structure, it was observed that higher levels of relative humidity prevailed in the vegetated structure, even under lower temperatures. This fact indicates the moisture influx due to vegetation transpiration into the vegetated structure. Based on the combined influence of temperature and relative humidity in determining heat index, the additional moisture supply increases the relative humidity in the vegetated structure, offsetting the temperature attenuation promoted by the vegetation.

The addition of vegetation to walls and roof increase the thermal performance quantified by the U-value parameter that indicates the amount of heat transferred through a surface. Low U-values indicate good levels of thermal insulation, whereas high U-values indicate the opposite. Wong et al [13] identified in a originally nonthermal insulating building a reduction in U-value from 2.39 to $1.19 \mathrm{~W} / \mathrm{m}^{2} \mathrm{~K}$ after its roof covered with turf. In addition, Alcazar \& Bass [14] and Castleton [15] also evidenced the role of vegetation in reducing U-value. According to Castleton [15] the addition of vegetation to walls and roofs increases not only insulation, but also thermal mass that comprises the materials potential to retain energy, and thus, provide inertia against temperature fluctuations. As a result, in the vegetated structure there is a temperature peak delay when compared to the nonvegetated structure.

The heat stress evaluation is shown according the histogram in Fig. 4 that compares the heat index of the vegetated and the non-vegetated structures over 92 days, according to the percentage of time that their values lie on the heat advisory categories shown in table 1.

According to Fig. 4 the adoption of combined systems of vegetated walls and roofs reduced the percentage of time under conditions from caution to danger in about $19 \%$ of cases. In terms of extreme heat conditions, the extreme caution episodes were reduced from $7.6 \%$ to $0.4 \%$ and the danger conditions from $4.1 \%$ to $0 \%$. 


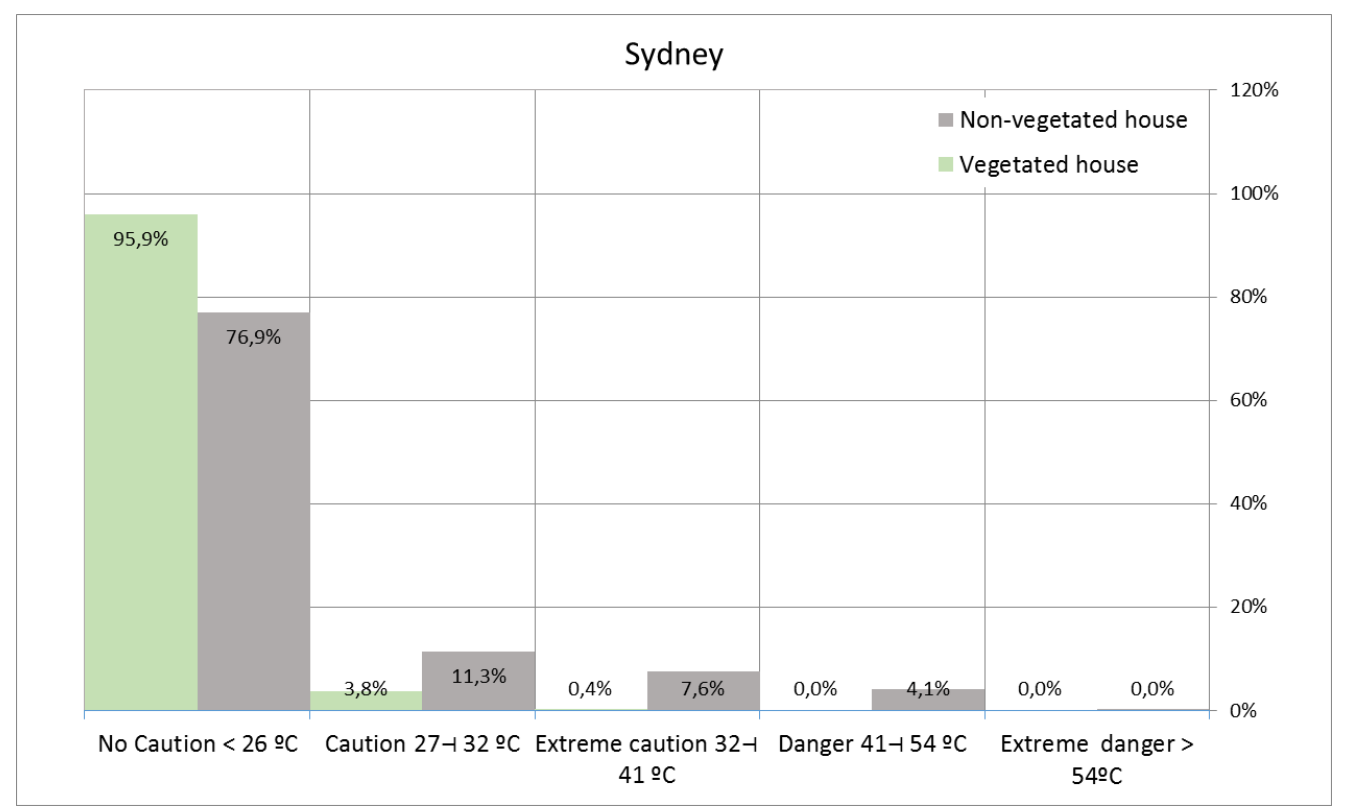

FIGURE 4. Comparison between Non-vegetated and vegetated houses in relation to percentage of time, along 92 days according to the Classification of heat advisories in United States - NWS (2016).

\section{CONCLUSIONS}

The modular system used in the experimental setup has shown good potential in heat index attenuation. However, in tall buildings it is important to note that the cooling effect of vegetated roofs will only extend to few floors below the roof. Thus, in terms of improving general thermal comfort it is important to consider the addition of vegetation to building facades.

The temperature attenuation observed was significant when comparing vegetated to non-vegetated structures. It is important to highlight that the dark blue colour used on prototype's walls increased the temperature differences observed more due to heat absorption by dark surfaces of the non-vegetated structure in contrast to shaded walls by the vegetated structure.

The relative humidity levels of the vegetated structure was higher along almost all of the data set indicating that the moisture influx into vegetated structure is due to transpiration of the plants.

The heat index depends on the simultaneous combination of temperature and relative humidity in order to assess the role of vegetated surfaces in thermal comfort promotion. So, the eventual moisture influx due to the plants' transpiration into the vegetated structure can offset the temperature attenuation observed, and increases the heat index values.

It is important to consider that moisture influx may also be attributed to experimental particularities, such as small openings between the roof and walls and also due to walls' porosity. It is expected that the use of coatings will increase the impervious properties of the walls, as well as a sealing the joint between the roof covering and the walls, will prevent any moisture ingress into the structure. Although the experimental scale of the experimental setup presented here is modest, it is important to take into account the combined effect of the vegetated roof and walls in heat index attenuation. Moreover, it is expected that vegetated walls can contribute integrally as a cooling mechanism, especially in floors of buildings where there is no contact with roof top areas

With regards to thermal comfort assessment, the classification of heat advisories is based on heat index limits which are categorized to evaluate the risk of possible heat disorders for people in high risk groups. According to observations presented in the results, the combination of the vegetated walls and roofs reduced the percentage of time under conditions from caution to danger by approximately $19 \%$. Extreme heat conditions, extreme caution and danger episodes were reduced correspondingly from $7.6 \%$ to $0.4 \%$ and from $4.1 \%$ to $0 \%$, respectively.

The combination of the vegetated walls and roof is shown to have a significant influence in promoting thermal comfort, keeping buildings in good health without the use of air conditioning systems, which, in turn, can lead to substantial energy savings. Thus, it is important to bear in mind that the use of off grid technologies not only 
improves welfare conditions, but also has indirect effects that can improve environmental conditions and lower the demand for energy generation for cooling environments.

\section{REFERENCES}

1. RICS Futures: Our Changing World. Accessed on 13th August 2016 from www.rics.org (2016)

2. Intergovernmental Panel on Climate Change, Climate Change - Impacts, Adaptation and Vulnerability: Regional Aspects. Cambridge University Press (2014).

3. R Basu,. and J. M.Samet, "Relation between elevated ambient temperature and mortality: a review of the epidemiologic evidence", Epidemiologic reviews, 24), 190-202 (2002).

4. G. Luber, and M. McGeehin," "Climate change and extreme heat events", American journal of preventive medicine 35, 429-435 (2008).

5. S. J. Wilkinson and R. Castiglia Feitosa, "Thermal Performance In Green Roof Retrofit," in Green Roof Retrofit: building urban resilience, edited by S. J. Wilkinson and T. Dixon (Wiley-Blackwell, London, 2016), pp. 62-84.

6. K. Perini, M. Ottelé, A. L .A. Fraaij, E. M. Haas, R. Raiteri, "Vertical greening systems and the effect on air flow and temperature on the building envelope", Building and Environment, 46, 2287-2294 (2011).

7. O. Mertz, K. Halsnaes, J. E. Olesen and K. Rasmussen, "Adaptation to climate change in developing countries", Environmental management 45, 743-752 (2009).

8. M. Ignatieva, and K. Ahrné, "Biodiverse green infrastructure for the 21st century: from "green desert" of lawns to biophilic cities", Journal of Architecture and Urbanism, 37, 1-9 (2013).

9. S. J. Wilkinson and R. Castiglia Feitosa, "Retrofitting Housing with Lightweight Green Roof Technology in Sydney, Australia, and Rio de Janeiro, Brazil”, Sustainability 7, 1081-1098 (2015).

10. G. B. Anderson, M. L. Bell, R.D. Peng, "Methods to calculate the heat index as an exposure metric in environmental health research', Environmental Health Perspectives", Environmental Health Perspectives 10, 1111-1119 (2013).

11. R. G. Steadman, "The assessment of sultriness. Part I: A temperature-humidity index based on human physiology and clothing science", Journal Applied Meteorology 18, 861-873 (1979).

12. NWS (National Weather Service), Meteorological Conversions and Calculations: Heat Index Calculator. Available: http://www.hpc.ncep.noaa.gov/html/heatindex. html [accessed 10 December 2016].

13. N. H. Wong, D. K. W. Cheong, H. Yan, J. Soh, C.L. Ong, A. Sia, "The effects of rooftop garden on energy consumption of a commercial building in Singapore", Energy and Buildings 35, 353-364 (2003).

14. S. Alcazar, B. Bass "Energy performance of green roofs in a multi storey residential building in Madrid", in Greening Rooftops for Sustainable Communities; Green Roofs for Healthy Cities, Washington, DC, USA, (2005)

15. H. Castleton, "Green roofs: building energy savings and the potential for retrofit", Energy and Buildings $\mathbf{4 2}$, 1582-1591 (2010). 